\title{
DIACHRONIC RECONSTRUCTION OF LOST CULTURAL HERITAGE SITES. STUDY CASE OF THE MEDIEVAL WALL OF AVILA (SPAIN)
}

\author{
P. Rodríguez-Gonzálvez ${ }^{2,1}, *$, S. Cardozo Mamani ${ }^{1}$, A. Guerra Campo ${ }^{1}$, L.J. Sánchez-Aparicio ${ }^{1}$, S. del Pozo ${ }^{1}$, A. Muñoz-Nieto ${ }^{1}$, \\ D. González-Aguilera ${ }^{1}$ \\ ${ }^{1}$ TIDOP Research Group. Department of Land and Cartographic Engineering, High Polytechnic School of Avila, University of \\ Salamanca, Spain - (pablorgsf, simoncm, agc, daguilera, luisj, s.p.aguilera, almuni)@usal.es \\ ${ }^{2}$ Department of Mining Technology, Topography and Structures, Universidad de León, Ponferrada, Spain - p.rodriguez@unileon.es
}

Commission II, WG II/8

KEY WORDS: 4D Modelling, Cultural Heritage, Data Fusion, Monitoring, Visualization

\begin{abstract}
:
The integration of the fourth dimension into the geospatial data allows to generate a diachronic model of Cultural Heritage $(\mathrm{CH})$ assets, namely, a set of 3D models to represent it in various historical phases. This kind of reconstruction pursues a better understanding of the $\mathrm{CH}$ site/scenario, enriching the historical hypotheses as well as contributing to the conservation and decisionmaking process. Although the new geotechnologies have reduced the amount of fieldwork, the generation of 4D model implies the interpretation of heterogeneous historical information sources and their integration. However, this situation could reach a critical point when the study elements are no longer present. Their reconstruction will allow the digital preservation and maintenance of our culture. The main challenge is to harmonize the different historical and archaeological data sources available in relation with the current remains, to recover the lost $\mathrm{CH}$ assets with a high degree of reliability. This manuscript aims to examine the study case of a diachronic reconstruction by means of the use of the geotechnology Mobile Laser System (MLS) and reverse engineering techniques for a lost urban CH element, the citadel or Alcázar Gate of Ávila. Within this aim, the derived product is evaluated in terms of the achieved accuracy to assess its suitability on the basis of constructive interpretations required to integrate the historical sources in relation to current remains and the surrounding.
\end{abstract}

\section{INTRODUCTION}

Geotechnologies can be defined as the set of sensors and computer algorithms that allows the acquisition, modelling and analysis of spatial features (individually or together) focused on knowledge generation for any level of detail and discipline that have to manage changes in space and/or time.

The increasing emergence of different geotechnologies for Cultural Heritage $(\mathrm{CH})$ recording and monitoring, together with the participation of different disciplines, makes the $\mathrm{CH}$ management and valorisation a complex task in which scientists, developers and final users aim to encourage cooperation and practice sharing.

This paper presents an approach to this goal through the diachronic reconstruction of lost cultural heritage sites, in our case the Alcázar Gate and its surroundings which belongs today to the Medieval Wall of Avila (Spain), declared Good of Cultural Interest by UNESCO in 1982.

With the aim of studying the current state and the geometry of a $\mathrm{CH}$ element, various geotechnologies can be used: from airborne to ground level, such as laser scanning, photogrammetry, or global navigation satellite systems (TorresMartinez et al., 2016). Their fusion and hybridization are being studied, and in spite of several approaches available (Ramos and Remondino, 2015), this issue still represent a hot topic for the Scientific Community (Chen et al., 2017). The registered point clouds can be reconstructed to provide a parametric modelling of the historical building (Dore and Murphy, 2012), or by means of non-parametric shapes (González-Aguilera et al., 2012). However, the main problem remains when these $\mathrm{CH}$ elements only exist partially due to different reasons. In this case, anastylosis approaches (Reilly, 1990) are the best way to reconstruct the whole $\mathrm{CH}$ element (Remondino, 2011; Nocerino et al., 2018) but sometimes requires the human expertise and knowledge about available historical documentation. The expert and the informal knowledges, underlying the interpretation of historical data and its circumstances, are vital for a correct reconstruction of the $\mathrm{CH}$ element (Micoli et al., 2013).

The historical information is very heterogeneous, encompassing texts, paintings, engravings, old photographs, maps, etc. On the contrary, the archaeological data sources include excavated material, standing monuments, inscribed records... and they can be used as an objective reference to shape historical data sources. Moreover, the anastylosis process has to deal with the lack of objectivity and mutual coherence of historical data, due to ancient surveys error and/or conservations distortions (Guidi and Russo, 2011). Last but not least, the alignment of components in a cartesian space presents various challenges. It is not only difficult from a practical point of view, but also additionally complicated by the fact that the original shape of the object to be reconstructed is only known with a certain probability. Virtual reconstruction is a manual process based on knowing to where every single part belongs (Cipriani and Fantini, 2017).

$3 \mathrm{D}$ metric survey of the current remains serves as a base, not only to establish the transition to the missing parts, but also to evaluate, in the common areas, the likelihood of the

* Corresponding author 
constructive hypotheses derived from the interpretation of the historical sources.

Once the anastylosis process has been solved, a dynamic evolution of $\mathrm{CH}$ assets across different spatial scales is accessible, allowing the possibility to better understand the present status of $\mathrm{CH}$ according to its history (RodríguezGonzálvez et al., 2017a). However, there are numerous challenges in order to carry out 4D modelling. This paper aims to solve these challenges using the Alcázar Gate and its surroundings as a case of study.

\section{STUDY CASE}

The Medieval Wall of Avila is the universal symbol and the most outstanding monument of the city of Ávila (Spain). Its importance derives of being the best preserved medieval walled enclosure in Spain. The walls are a very important factor in shaping urban planning in the city and historically they have participated in the distribution of urban space among the various social groups that have inhabited Ávila. In particular, the Alcázar Gate is the most solemn element of the entire wall. This gate is constituted by two large towers joined by a bridge (which is a unique and a singular element between the European walls) that reinforces the defense of access.

There is no record of an exact date of the beginning of the construction of the Alcázar Gate (or citadel), but we can know from the history of the city of Ávila that the Alcázar Gate dates back to the second half of the 12th century, as indicated by the letters of Sancho IV addressed to the income collectors (Georges, 1929). However, the oldest graphic document that can be found is a painting belonging to the painter Anton Van der Wyngaerde who, on behalf of Philip II, paints the city of Avila in 1570. Due to its dilapidated state of conservation, in 1584 a direct intervention is carried out by Felipe II. The Alcázar Gate continues to be restored and modified, and already in the eighteenth century the Alcázar Gate definitely lost its status as a fortress to go through different uses. In 1749, with the cession of Fernando VI, the Alcázar Gate became a fortress and numerous reforms as opening windows, even demolishing two cubes of the wall and reducing the height of another, were done.

In the outer walls of the Alcázar Gate were found patrimonial elements that today no longer exist, such as the house of the Alhóndiga, build, in 1590, from the southern tower of the Alcázar Gate, that was, formerly, an establishment where people sold, bought and even stored grain. This building throughout its history had different uses, cereal market, jail of notables, barracks of the civil guard and, before its demolition in the year 1882 .

\section{MATERIALS}

\subsection{Geotechnologies}

Recent advances in Geomatics Science enable the use of a wide range of sensors to record, catalogue and analyse $\mathrm{CH}$ sites in their current state: from the RGB and multispectral cameras, to the Terrestrial Laser Scanner (TLS), Airborne Laser Scanner (ALS), drones or even Mobile Laser Systems (MLS) (Stylianidis and Remondino, 2016). For the study case (section 2), the MLS is employed as a data source for recording the present state of the current remains. The suitability of MLS for documentation and dissemination of $\mathrm{CH}$ is described in (Toschi et al., 2015) (Rodriguez-Gonzalvez et al., 2017b). The technical specifications of the employed MLS are listed in Table 1.

\begin{tabular}{cc}
\hline Parameter & Value \\
\hline$X, Y$ position & $0.020 \mathrm{~m}$ \\
$Z$ position & $0.050 \mathrm{~m}$ \\
Roll and pitch & $0.005^{\circ}$ \\
True heading & $0.015^{\circ}$ \\
Measuring principle & Time of Flight (ToF) \\
Maximum range & $200 \mathrm{~m}$ \\
Range precision & $8 \mathrm{~mm},(1 \sigma)$ \\
Range accuracy & $\pm 10 \mathrm{~mm},(1 \sigma)$ \\
Laser measurement rate & $75-500 \mathrm{kHz}$ \\
Measurement per laser pulse & $\mathrm{Up} \mathrm{to} 4$ simultaneous \\
Scan frequency & $80-200 \mathrm{~Hz}$ \\
Laser wavelength & $1550 \mathrm{~nm}(\mathrm{near}$ infrared) \\
Scanner field of view & $360^{\circ}$ \\
Operating temperature & $10^{\circ}-40^{\circ} \mathrm{C}$ \\
Angular resolution & $0.001^{\circ}$ \\
\hline
\end{tabular}

Table 1. Technical specifications of Optech LYNX Mobile Mapper.

The MLS measurement process is not completely straightforward. The initial planning phase of the data acquisition will constraint the final results in both completeness and precision issues. The completeness is directly linked to the complexity of the scenarios, which in $\mathrm{CH}$ are usually high, and the areas where the vehicle is allowed to transit.

In terms of precision, the MLS dependence of GNSS signal will cause a precision degradation in scenarios with a weak satellite geometry, such as narrow streets in the case of urban $\mathrm{CH}$ assets (Toschi et al., 2015). Besides, the precision of the acquired point cloud is related to the laser angle of incidence (Chu and Chiang, 2012). Moreover, the MLS calibration uncertainty is directly propagated to the recorded object, which could cause a lack of overlapping between scans of the same scene acquired from different trajectories. All these issues imply a constant control of the scanning process and the planning phase.

At this point the recent advances in portable laser scanners (Nocerino et al., 2017) will dismiss the completion and GNSS constraints commented previously.

\subsection{Historical sources}

For the present study case, the most reliable historical resources are found in the plans of Juan Gómez Parral of 1749 (Figure 1a), and the plan of Pedro Moreau of 1750 (Figure 1b) in the conversion of the citadel to barracks. In this reform, according to the legend, a plant was built for the barracks inside which masonry arches are made, a square and a guard portal are created, as well as bedrooms and a gallery. We must highlight the opening of windows and the construction of an official gallery. The latter is of great importance since, as a consequence, two towers belonging to the Alcázar were demolished on the South canvas and the height was reduced in six rows of the Polvorín tower. The Alcázar is again in a ruinous state according to a report dated in 1780 , and the reforms carried out in 1806 and 1813 do not solve the serious problem of deterioration. From this moment, the nineteenth and twentieth centuries lead to the total destruction of the Alcázar (1930).

Among all data sources used for the diachronic reconstruction, the bests are those based on ancient drawings which can provide a large amount of suitable information. However, their reliability is typically unknown. These documents present great contradictions among them and also with reality. 


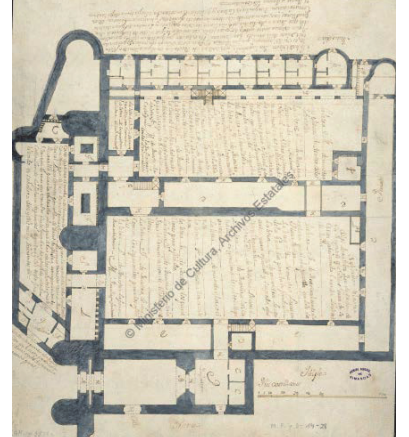

(a)

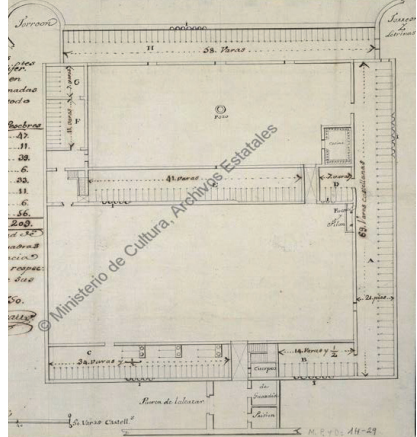

(b)
Figure 1. Different historical sources employed. (a) Juan Gómez Parral, 1749 (AGS. MPD, 14, 028). (b) Pedro Moreau, 1750 (AGS. MPD, 14, 029). Source: National Archive of Simancas (Spain).

Other historical documents employed and analyzed were:

- Historical photographs.

- Maps.

- Written testimonies.

To collect them it was necessary to perform an intensive documentation work of the element under study. The knowledge coming from these sources was added and weighted in the analysis by means of constraints about the buildings materials, constructive techniques and additional geometric constraints of those buildings that do not exist currently.

The role played by the different data sources is related to their antiquity since present intrinsic inconsistencies, especially further back in time. In the case of the graphical material, old photographs are the most reliable, although they only cover a small temporal interval. These historical photographs used to be oblique and thus allow the single view reconstruction approach developed by (Aguilera and Lahoz, 2006) (García-Gago et al., 2014), being able to extract geometric proportions, and even a partial reconstruction depending the geometry of the shot.

In the present study case, a total of three individual old images from c. $1860-1870$ were considered. They cover a temporal keyframe, where some extramural buildings were modified. They played a key role along with the plans, since they provided objective information, in spite of the lack of scale or another direct metric information.

The other graphical source was a city plan from c. 1865, whose use in the project is marginal. Its low resolution, due to the small scale (around 1:10,000), has limited the accurate location of the surroundings of extramural buildings, e.g. the circular fountain.

Finally, the written testimonies, which cover a temporal framework from c. 1860 to 1870 , and an isolated one from c. 1935 describe the geometry of the citadel, the defensive system or the transformation suffered by the asset. In spite of being non-graphical, they were used as a constraint source when there was not graphical information available or there were discrepancies between the graphical information, the constructive hypothesis and/or the current remains.

\section{EXPERIMENTAL RESULTS}

From the different data sources stated previously, the reconstruction process was divided in the following steps:

- Recording and 3D reconstruction of the current state of the Alcázar Gate and its intramural and extramural sections using different geotechnologies.

- Diachronic reconstruction or 4D modelling of the Alcázar Gate based on the historical documents for two different temporal intervals.

- Diachronic reconstruction or 4D modelling of the extramural and intramural buildings of the Alcázar Gate prior to their demolishment.

The reconstruction of the current state will provide the basis for the anastylosis process and also will be essential to anchor the plausible reconstruction of the lost building elements.

This first phase required the classical steps of 3D modelling: to filter the non-desirable elements of the point cloud (e.g. pedestrians, cars, etc.) and the segmentation of the study area.

The extraction of the basic primitives was done on the basis of cross sections. This process involves a generalization operation and a loss of accuracy due to the idealization of regular shapes (i.e. planes, cylinders, etc.). The addition of certain constraints, such as parallelism of the façades with the plumb line (Figure 2) also contributed to idealization and loss of reliability. The fidelity of the $3 \mathrm{D}$ reconstruction is addressed more deeply in subsection 4.3.

\subsection{Intramural buildings}

It involved two temporal stages according to the amount and type of historical information available. The first diachronic reconstruction corresponded to the most modern, after 1750 when the Alcázar Gate (or citadel) was converted to barracks. In this stage the ancient drawings were vectorized and fitted according to the present remains.

The ancient drawings were already digitalized, but the scalebar was in ancient units, so the vectorization was fitted to the current remains. In this step, the spatial invariants of the old drawings do not verify a simple geometric transformation, being the discrepancies very large and not homogeneous. As a result, they were used in a relative way, namely, reconstructing the relative position of lost elements considering the current remains. Thanks to old photographs of the demolition process, the interior walls width was incorporated. Also, the written testimonies informed about the demolition of the two south towers c. 1792, being the amount of anchor elements reduced. One of the main key issues of this stage was the lack of

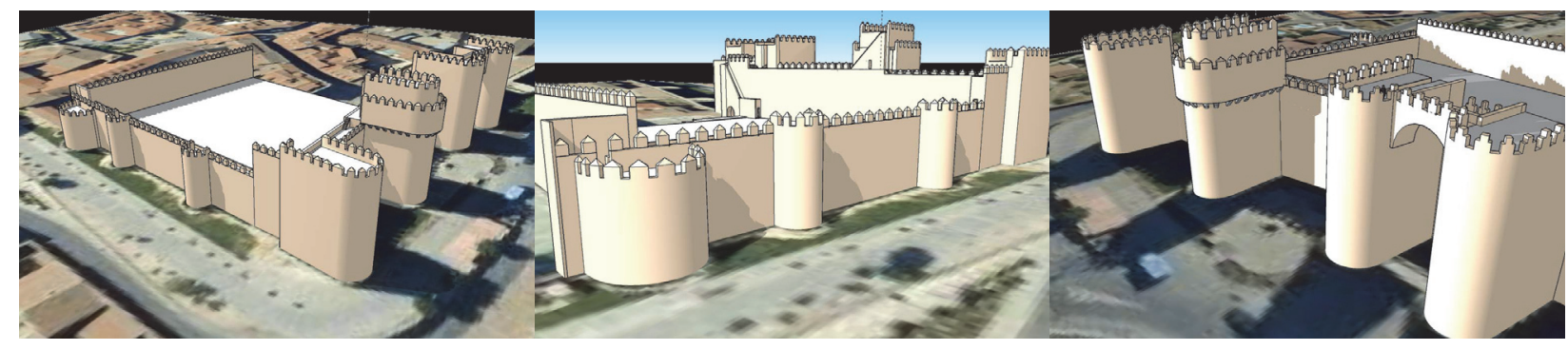

Figure 2. Different view of the reverse engineering process corresponding to the current state. 
information about the heights of buildings. From the written documentation it was reflected that the building consisted of three floors, except the officers' gallery which only had two. According to historical data its height was 11 feet. This measurement is not accurate but enough to provide a supported hypothesis. Moreover, in the old photographs was detected a passage concordant with the written testimonies about the officer's gallery that allowed the communication among the buildings avoiding the courtyards. This hypothesis is reasonable in terms of both military and climatological conditions. The final plausible reconstruction is shown in Figure 3.

The second diachronic reconstruction refers to the "real" Alcázar Gate, when it was used as a citadel. The main problem of this stage was the lack of reliable historical information. We hardly had a few written testimonials and some stones that gave us clues to the volume of the Alcázar. There was necessary to employ constructive hypothesis based on similar medieval military constructions, such as the interior defensive walls, or the existence of the northwest turret (supported by the presence of a foundation). The likelihood of the 4D model generated (Figure 4) was reduced, as expected, by the combination of surveyed data and philological analysis (Rodríguez-Gonzálvez et al., 2017a).

\subsection{Extramural buildings}

On the basis of the 4D modelling of the current remains, the anastylosis process was carried out based on several photographic sources which reduced considerably the uncertainty associated to the final $4 \mathrm{D}$ model. The process is similar to described in the previous subsection, being the most remarkable difference caused by the nature of the historical source, in this case, old photographs.

The first issue is that extramural buildings disappeared and there are not current remains. The only anchor elements are the walls, which will be used to estimate the photographs scale. Secondly, the historical images have vanishing points, being necessary their identification to carry out the reconstruction (Aguilera and Lahoz, 2006). The modelling was carried out in two phases, being the first the coarse modelling of building blocks, as idealized prisms (e.g. orthogonality between façades, round angles, etc.). They were scaled on the basis of identifiable elements of the Wall. The older the photograph, the higher the uncertainty due to the changes suffered by the Wall, especially by the rehabilitation and conservation interventions. For the older images, there was employed the distance between some stones. That allowed a reasonable reconstruction of the 4D model.

For the most representative extramural building, the Alhóndiga, the old photographs were used to vectorize and reconstruct the façade (e.g. elements doors, windows, columns, etc.). The different façades were segmented and projected according to their vanishing lines and the sub-image was fitted in the 3D model to add the details. Due to the different point of views, not the same historical photographs were used for all the buildings. Besides, the historical photographs were used to map texture, improving the realism of the final result (Figure 5 and 6). In the case of overlapping between different photographs, there was not carried out any blending process or radiometric modification.

Since, the historical images were registered in relation to the 3D coordinate system, it was possible to replicate the original point of view and compare both, or add a current image in a similar way that re-photographing techniques (Nocerino et al., 2012).

\subsection{Accuracy assessment}

The original MLS point cloud was compared against the current stated CAD modelling, focusing on the extramural and intramural section of the Alcázar Gate. The accuracy analysis was carried out with CloudCompare (CloudCompare, 2018) to compute the signed discrepancies against the reconstructed mesh and the point cloud (Figure 7). The non-modelled elements (e.g. rocks, artificial elements attached to the Wall, etc.) were manually segmented.

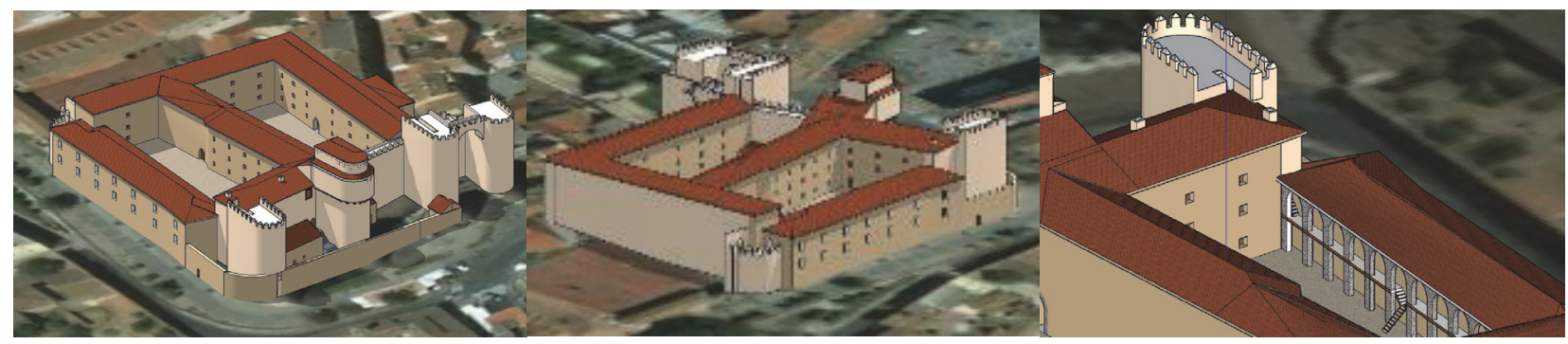

Figure 3. Intramural buildings: different views of the Alcázar after 1750

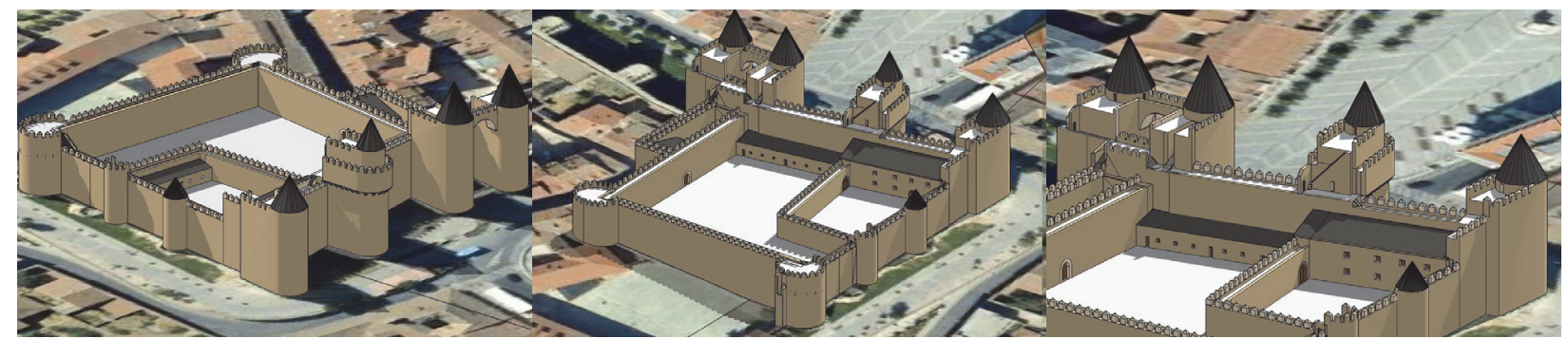

Figure 4. Intramural buildings: different views of the CAD modelling of the Alcázar anastylosis previous to mid-eighteenth century. 


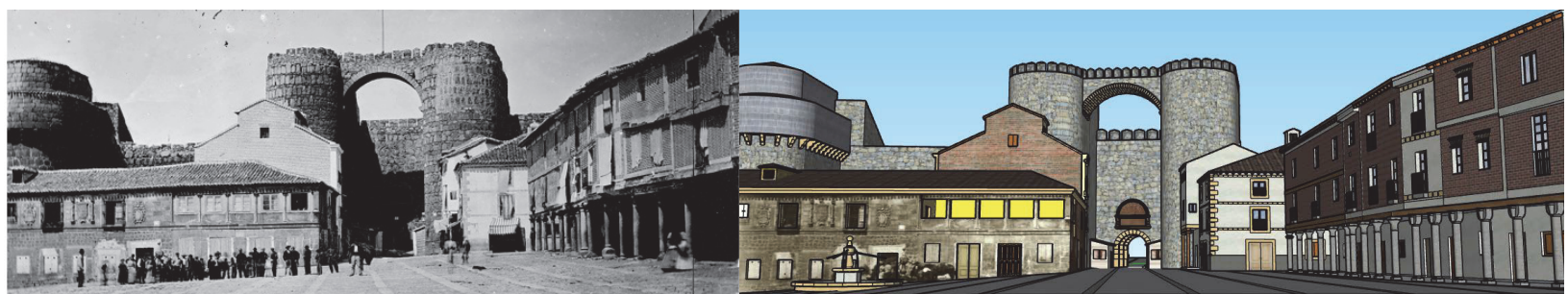

Figure 5. Extramural buildings: Old photograph texture integration (Laurent, c. 1865, Ruiz Vernacci Archive, VN-17214) with 4D modelling for the extramural section of the Alcázar Gate. Source: Cultural Heritage Institute of Spain (IPCE).

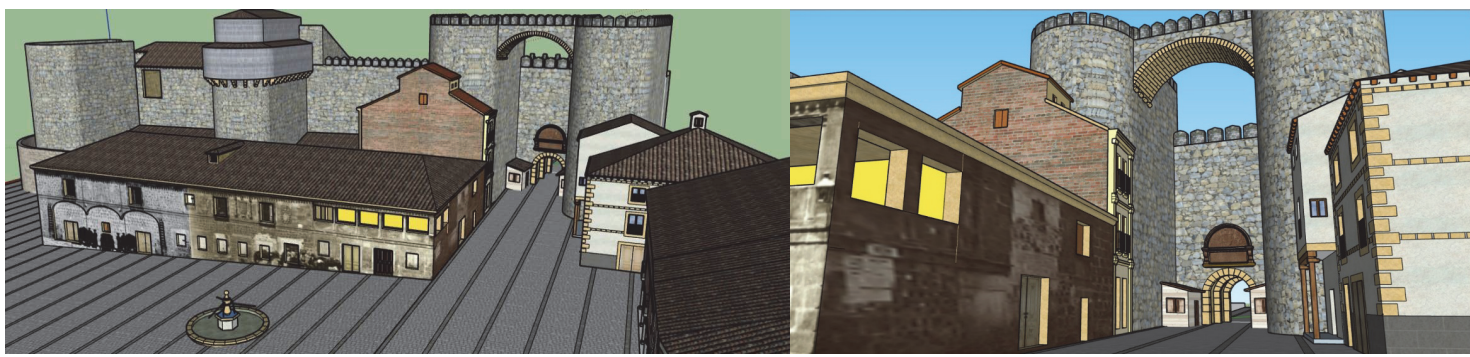

Figure 6. Extramural buildings: different views of the 4D modelling of the Alcázar Gate surroundings, mid-nineteen century.

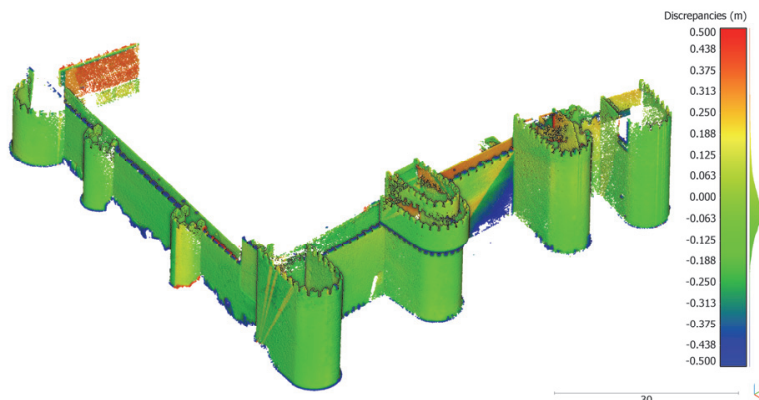

Figure 7. Spatial view of the signed discrepancies in the Alcázar Gate and its surroundings.

To determine if the discrepancies (Figure 7) follow a Gaussian distribution, a graphical normality test is employed due to the high amount points. The large amount of points was the reason because the numerical normality tests do not work properly (Rodríguez-Gonzálvez et al., 2014). In the Figure 8b are shown the quantiles of the empirical distribution plotted against the theoretical quantiles of the normal, or Q-Q plot (Höhle and Höhle, 2009). The deviations from the straight line indicates that the distribution of the errors is not normal.
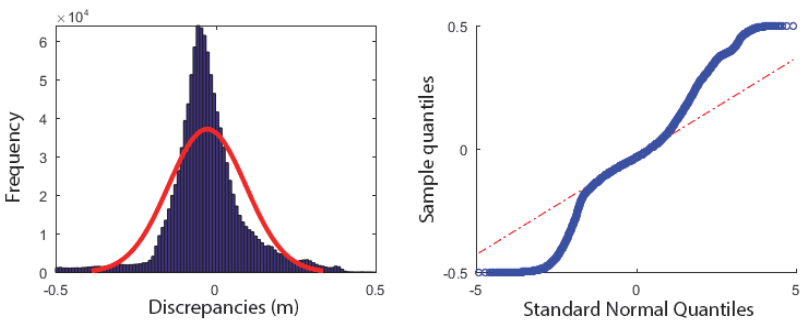

Figure 8. (a) Histograms of the signed discrepancies with the superimposed curve for the normal distribution and (b) Q-Q plot of the distribution of the signed discrepancies

In Table 2 is summarized the robust assesmment as well as the Gaussian ones for comparative purposes. The non-parametric estimators adopted for the central tendecy is the median while for the dispersion are employed the normalized median absolute deviation (NMAD) and the square root of the biweight midvariance (BWMV) (Nocerino et al., 2017).

$$
\begin{gathered}
\text { NMAD }=1.4826 \cdot \mathrm{MAD} \\
\mathrm{BWMV}=\frac{n \sum_{i=1}^{n} a_{i}\left(x_{i}-m\right)^{2}\left(1-U_{i}^{2}\right)^{4}}{\left(\sum_{i=1}^{n} a_{i}\left(1-U_{i}^{2}\right)\left(1-5 U_{i}^{2}\right)\right)^{2}} \\
a_{i}=\left\{\begin{array}{l}
1, \text { if }\left|U_{i}\right|<1 \\
0, \text { if }\left|U_{i}\right| \geq 1
\end{array}\right. \\
U=\frac{x_{i}-m}{9 \cdot \mathrm{MAD}}
\end{gathered}
$$

being the $m$ the median of the sample (x) composed of $n$ points.

\begin{tabular}{lcc} 
& Parameter & Value \\
\cline { 2 - 3 } & Number of points & 1122289 \\
\hline \multirow{3}{*}{ Gaussian } & Mean & $-0.026 \mathrm{~m}$ \\
assessment & Standard deviation & $\pm 0.121 \mathrm{~m}$ \\
& Kurtosis & 2.65 \\
& Skewness & 0.11 \\
\hline \multirow{4}{*}{ Robust } & Median & $-0.036 \mathrm{~m}$ \\
assessment & NMAD & $\pm 0.078 \mathrm{~m}$ \\
& Sqrt(BWMV) & $\pm 0.096 \mathrm{~m}$ \\
& Quartile 0.25 & $-0.084 \mathrm{~m}$ \\
& Quartile 0.75 & $0.024 \mathrm{~m}$ \\
\hline
\end{tabular}

Table 2. Statistical results of the anastylosis process for the current remains.

As shown in table 2, there is a small bias (less than $4 \mathrm{~cm}$ ) due to the idealization process to regular shapes, but it is within the expected error for this kind of diachronic reconstructions. Moreover, the error dispersion is overestimated by the Gaussian assessment ( $\pm 12 \mathrm{~cm}$ versus $\pm 8 \mathrm{~cm}$ ), being more appropriate the robust assessment to characterize it.

In view of the results, and according to the discrepancies distribution in the histogram, $95 \%$ of the modeled points have an error in the range of $[-0.303,+0.266]$ meters. Besides it can be observed that the hypothesis of a Gaussian distribution the 
3D modeling error in the preserved zone at $95 \%$ of confidence is \pm 0.154 meters.

\section{CONCLUSIONS}

The present contribution has a double objective, on the one hand, the 4D modelling of a heritage element through reverse engineering and fusion of information, and on the other hand, to know if the results in terms of its accuracy would reach acceptable values.

The main key issue was the added difficulty due to the lack of knowledge about an element disappeared, being necessary to use constructive interpretations in some parts of the $\mathrm{CH}$ elements, with the consequent implications in the derived analysis. Another issue to point out is the large amount of time involved in the anastylosis operation. There are reverse engineering modelling techniques that are semi-automatic and there are assistance tools for basic normal geometries. However, in this case, due to the non-primitive elements (free forms), the modelling process is not traceable, implying a very high number of working hours.

Regarding the accuracy of the results, it is concluded that the CAD model has an accuracy of centimeters, resulting a suitable methodology in reverse engineering applications in heritage and architectural elements. The improvement of the modelling software tools will increase the precision, but up to a threshold due to the aforementioned constructive hypothesis.

\section{ACKNOWLEDGEMENTS}

The authors wish to express our gratitude for the support of the European Union through the Joint Programming Initiative on Cultural Heritage (JPI-CH), for funding the project Cultural Heritage Through Time $\left(\mathrm{CHT}^{2}\right)$, as well as to the Ministry of Economy and Competitiveness of Spain.

\section{REFERENCES}

Aguilera, D. G., Lahoz, J. G., 2006. sv3DVision: didactical photogrammetric software for single image-based modeling. In: The International Archives of the Photogrammetry, Remote Sensing and Spatial Information Sciences, Tokyo, Japan, Vol. XXXVI-Part 6, pp. 171-178.

Chen, B., Huang, B., Xu, B., 2017. Multi-source remotely sensed data fusion for improving land cover classification. ISPRS Journal of Photogrammetry and Remote Sensing, 124 (Supplement C), pp. 27-39.

Chu, C. H., Chiang, K. W., 2012. The performance of a tight INS/GNSS/photogrammetric integration scheme for land based MMS applications in GNSS denied environments". In: The International Archives of the Photogrammetry, Remote Sensing and Spatial Information Sciences, Melbourne, Australia, Vol. XXXIX-B1, pp. 479-484.

Cipriani, L., Fantini, F., 2017. Digitalization culture vs archaeological visualization: integration of pipelines and open issues. In: The International Archives of the Photogrammetry, Remote Sensing and Spatial Information Sciences, Nafplio, Greece, Vol. XLII-2/W3, pp. 195-202.

CloudCompare, 2018. Version 2.9.1. [GPL software]. Retrieved from http://www.cloudcompare.org/ [Accessed 26th of January 2018].
Dore, C., Murphy, M., 2012. Integration of historic building information modeling (HBIM) and 3D GIS for recording and managing cultural heritage sites. In: 18th International Conference on Virtual Systems and Multimedia, Milan, Italy, pp. 369-376.

Georges, C., 1929. Mercedes Gaibrois de Ballesteros, Sancho IV de Castilla. T. I. Bulletin Hispanique, 31(2), pp. 156-159.

Garcia-Gago, J., Gomez-Lahoz, J., Rodríguez-Méndez, J., \& González-Aguilera, D., 2014. Historical single image-based modeling: The case of Gobierna Tower, Zamora (Spain). Remote Sensing, 6(2), pp. 1085-1101.

Gonzalez-Aguilera, D., Del Pozo, S., Lopez, G., RodriguezGonzalvez, P., 2012. From point cloud to CAD models: Laser and optics geotechnology for the design of electrical substations. Optics \& Laser Technology, 44 (5), pp. 1384-1392.

Guidi, G., Russo, M., 2011. Diachronic 3D reconstruction for lost cultural heritage. In: The International Archives of the Photogrammetry, Remote Sensing and Spatial Information Sciences, Trento, Italy, Vol. XXXVIII-5/W16, pp. 371-376.

Höhle, J., Höhle, M., 2009. Accuracy assessment of digital elevation models by means of robust statistical method. ISPRS Journal of Photogrammetry and Remote Sensing, 64(4), pp. 398-406.

Micoli, L., Guidi, G., Angheleddu, D., Russo, M., 2013. A multidisciplinary approach to 3D survey and reconstruction of historical buildings. In: Digital Heritage International Congress, pp. 241-248.

Nocerino, E., Menna, F., Remondino, F., 2012. GNSS/INS aided precise re-photographing. In: $18^{\text {th }}$ International Conference on Virtual Systems and Multimedia, Milano, Italy, pp. $235-242$.

Nocerino, E., Menna, F., Remondino, F., Toschi, I., RodríguezGonzálvez, P. 2017. Investigation of indoor and outdoor performance of two portable mobile mapping systems. In: Videometrics, Range Imaging, and Applications XIV, Munich, Germany, Vol. 10332, p. 103320I.

Nocerino, E., Menna, F., Toschi, I., Morabito, D., Remondino, F., Rodríguez-Gonzálvez, P., 2018. Valorisation of history and landscape for promoting the memory of WWI. Journal of Cultural Heritage, 29, pp. 113-122.

Ramos, M. M., Remondino, F., 2015. In data fusion in cultural heritage - A review. In: The International Archives of the Photogrammetry, Remote Sensing and Spatial Information Sciences, Taipei, Taiwan, Vol. XL-5/W7, pp. 359-363.

Reilly, P., 1990. Towards a virtual archaeology. In: Computer Applications \& Quantitative Methods in Archaeology. British Archaeological Reports, Oxford, pp. 133-139.

Remondino, F., 2011. Heritage recording and 3D modeling with photogrammetry and 3D scanning. Remote Sensing, 3(6), pp. 1104-1138.

Rodríguez-Gonzálvez, P., Garcia-Gago, J., Gomez-Lahoz, J., González-Aguilera, D., 2014. Confronting passive and active sensors with non-gaussian statistics. Sensors, 14(8), pp. 1375913777. 
Rodríguez-Gonzálvez, P., Jiménez Fernández-Palacios, B., Muñoz-Nieto, Á. L., Arias-Sanchez, P., \& Gonzalez-Aguilera, D., 2017b. Mobile LiDAR System: new possibilities for the documentation and dissemination of large cultural heritage sites. Remote Sensing, 9(3):189, 17pp.

Rodríguez-Gonzálvez, P., Muñoz-Nieto, A. L., del Pozo, S., Sanchez-Aparicio, L. J., Gonzalez-Aguilera, D., Micoli, L., Gonizzi Barsanti, S., Guidi, G., Mills, J., Fieber, K., Haynes, I., Hejmanowska, B., 2017a. 4D Reconstruction and visualization of cultural heritage: analyzing our legacy through time. In: 3D Virtual Reconstruction and Visualization of Complex Architectures, In: The International Archives of the Photogrammetry, Remote Sensing and Spatial Information Sciences, Nafplio, Greece, Vol. XLII-2/W3, pp. 609-616.

Stylianidis, E., Remondino, F., 2016. $3 D$ recording, documentation and management of cultural heritage. Whittles Publishing, Scotland, UK.

Torres-Martínez, J., Seddaiu, M., Rodríguez-Gonzálvez, P., Hernández-López, D., González-Aguilera, D., 2016. A multidata source and multi-sensor approach for the $3 \mathrm{D}$ reconstruction and web visualization of a complex archaelogical site: The Case study of "Tolmo de Minateda". Remote Sensing, 8(7):550, $25 \mathrm{pp}$.

Toschi, I., Rodríguez-Gonzálvez, P., Remondino, F., Minto, S., Orlandini, S. Fuller, A., 2015. Accuracy evaluation of a mobile mapping system with advanced statistical methods. In: The International Archives of the Photogrammetry, Remote Sensing and Spatial Information Sciences, Ávila, Spain, Vol. XL-5/W4, pp. 245-253. 